\section{A influência do conceito de conteúdo de Twardowski na teoria da intencionalidade de Husserl}

\author{
Sávio Passafaro Peres ${ }^{1}$ \\ Pós-doutorando em Piscologia \\ Unesp-Assis (PNDP-CAPES)
}

Resumo: Nas Investigações Lógicas (1900/1901), Husserl defende que a fundamentação epistemológica da lógica pura exigia uma determinada teoria da intencionalidade, em que se distinguisse ato, conteúdo e objeto. Husserl encontra inspiração para essa teoria da intencionalidade na obra de Kazimierz Twardowski, Sobre o conteúdo e o objeto das representacóes (1894). Husserl aceita a tese de Twardoswski, de que o conteúdo faz a mediação entre o ato e o objeto. Mas Husserl, em virtude de seu antipsicologismo, reformula a teoria de Twardowski, ao assumir que a significação é um conteúdo ideal e não um conteúdo psíquico. Isso traz o problema, em Investigações Lógicas, da apreensão do significado ideal por um sujeito real, problema esse que encontra sua solução na teoria da instanciação.

Palavras-chave: Edmund Husserl, Fenomenologia, Kazimierz Twardowski, intencionalidade.

\begin{abstract}
In Logical Investigations (1900/1901), Husserl claims that the epistemological foundation of pure logic requires a certain theory of intentionality, in which is distinguished act, content and object. This conception is inspired by the work of Kazimierz Twardowski, On the Content and Object of Presentations (1894). Husserl accepts Twardoswski's position, according to which the content intermediate the relation between the act and the object. But Husserl, by virtue of his antipsychologism, reworks Twardowski's theory, assuming that the meaning is an ideal content and not a psychic one. This brings the problem, in Logical Investigations, of the apprehension of ideal meaning by a real subject, a problem which finds its solution in the theory of instantiation.
\end{abstract}

Key-words: Edmund Husserl, Phenomenology, Kazimierz Twardowski, intentionality. 
A influência do conceito de conteúdo de Twardowski na teoria da intencionalidade de Husserl

\section{Os Prolegômenos à lógica pura e a defesa da idealidade}

No prefácio das Investigações lógicas, Husserl afirma que pretende reestabelecer o status da lógica, a qual forma um continuum com a matemática (HUSSERL, 1900: iv, v, 178). Para ele, ambas são ciências teóricas dedutivas ideais, que versam sobre estruturas, objetos e leis ideais e não sobre processos psíquicos, ou vivências.

Não apenas um número é algo ideal, mas também os significados de enunciados científicos. Uma proposição [Saţ] é o significado ideal (ou o sentido) de um enunciado declarativo: "Quem assere: 'de dois juizos contraditórios, um é verdadeiro, o outro é falso' $[. .$.$] não visa asserir uma lei$ para atos de juízo, mas uma lei para conteúdos de juízos, por outras palavras, para significações ideais, que costumamos denominar, de modo abreviado, proposições." (HUSSERL, 2014:130). A proposição não pode ser confundida com sua expressão linguística. Da mesma forma, o número três não se altera caso seja representado em algarismos arábicos ou romanos: “3", "III" e "três", são expressões distintas que expressam o mesmo significado [Bedeutung] ou sentido [Sinn]. O significado não é algo real, mas sim algo ideal. Caracteriza-se por ser atemporal e por manter sua absoluta identidade consigo próprio. $\mathrm{O}$ sentido de um enunciado científico não é um estado psíquico privado e fugaz, mas é algo objetivo, intersubjetivamente acessível. Uma proposição, embora ela própria seja sempre ideal, pode se referir a algo real ou ideal (1900: 25). A proposição "o número 3 é impar" versa sobre um objeto ideal. A proposição, "esta casa é verde" versa sobre um objeto real.

Uma vez que uma proposição é algo ideal, também uma teoria o será, já que esta é "um sistema dedutivo de proposições" (HUSSERL, 1900: 243). Se cada teoria modificasse toda vez que fosse apreendida por um sujeito, isso significaria que haveria tantas teorias quanto são as pessoas, o que implicaria o relativismo e a própria impossibilidade da ciência.

\section{Condições objetivas e condições subjetivas do conhecimento}

Se, em Prolegômenos, Husserl busca demonstrar que a redução de entidades ideais a meros conteúdos psíquicos privados implica relativismo, um dos eixos das seis Investigações lógicas, publicadas um ano depois, no ano de 1901, gira em torno de elucidar a relação entre idealidade e sujeito psíquico. Em outras palavras, as duas partes de Investigações lógicas se complementam ao realizar uma dupla tarefa: estabelecer, de um lado, as condições de possibilidade ideais objetivas e, de outro lado, as condiçoes de possibilidade subjetivas do conhecimento teórico. A idealidade das significações é condição objetiva do conhecimento, mas não é condição suficiente. É preciso investigar também as condições subjetivas, afinal, "é evidente, a priori, que sujeitos pensantes devem ser em

Revista de Filosofia Moderna e Contemporânea

Brasília, vol 3, no 2, 2015. 
geral aptos a realizar todos os tipos de atos em que os conhecimentos teóricos [theoretische Erkenntnis] são feitos reais [realiziert]" (HUSSERL, 1900: 238). Desde então, a fundamentação da lógica pura exige uma análise da subjetividade epistêmica e, em particular, das vivências ligadas ao conhecer teórico.

O problema, portanto, que rege a segunda parte de Investigações lógicas, pode ser posto da seguinte maneira: se as proposições são objetivas e irreais (ideais), como é possível que elas sejam apreendidas por um sujeito real? Poderíamos dizer que o significado se encontra na consciência como conteúdo de uma vivência? Mas se ele se torna conteúdo de consciência, ele não se tornaria, por força, subjetivo, perdendo, portanto, sua objetividade? Esses problemas ocupam o centro da segunda parte de Investigações lógicas e são justamente eles que conduzem Husserl a elaborar uma forma peculiar de teoria da intencionaliadade, na qual o objeto é transcendente ao ato:

Para a consideração fenomenológica real [reell], a própria objetividade não é nada; para falar em termos gerais ela é transcendente ao ato. Independentemente de saber em que sentido e com que direito se fala de seu "ser", independentemente de saber se é real ou ideal, se é verdadeira, possivel ou impossivel, o ato está "dirigido para ela.” (HUSSERL 2012: 354)

Assim, Husserl, por um lado, abandona a teoria bipartite da intencionalidade de Brentano (1874), em que se distingue ato e conteúdo (ou objeto imanente), para se aproximar da teoria tripartite de Twardowski (1894), em que se distingue entre ato, conteúdo e objeto.

\section{A teoria tripartite da intencionalidade de Twardowski}

Durante a década de 1890, iniciou-se um debate entre os discípulos de Brentano concernente à teoria da intencionalidade presente em Psicologia do ponto de vista empirico. Ao invés de distinguir entre ato e conteúdo (objetividade imanente), como fizera Brentano, não seria melhor distinguir entre ato de representar, conteúdo representado e objeto representado? Um dos primeiros a oferecer um tratamento pormenorizado desta distinção tripartite foi Twardowski, que, em 1894, em Sobre a Doutrina do Conteúdo e do Objeto das Representações: uma Investigação Psicológica (2005: 46; 1894: 4), afirmou que Brentano fora bem sucedido em apontar uma ambiguidade no termo representação [Vorstellung], ao distinguir entre ato de representação [Vorstellungsakt] e conteúdo de representação [Vorstellungsinhalt]. Mas este último termo era, segundo o parecer de Twardowski, novamente ambíguo, razão pela qual ele propôs a ulterior distinção entre conteúdo de representação [Vorstellungsinhalt] e objeto de representação [Gegenstand der Vorstellung7. Segundo Twardowski, o conteúdo de representação é imanente ao ato psíquico, ao passo que o objeto "existe independente do pensamento[unabbängig vom Denken]" (2005: 46; 1894: 4).

Para Twardowski, o conteúdo é aquilo por meio do que o ato se dirige a um objeto transcendente "Nós dissemos que o conteúdo é o meio [das Mittel], através do qual o objeto [Gegenstand] é representado" (TWARDOWSKI, 1894: 18). Mas qual a relação entre o ato de representar e o objeto representado?

Twardowski, em particular, busca explicitar tal relação em analogia ao ato de pintar. No 
A influência do conceito de conteúdo de Twardowski na teoria da intencionalidade de Husserl

ato de pintar, algo é pintado, como, por exemplo, uma paisagem. Observemos que a expressão "paisagem pintada" possui uma ambiguidade. Pode referir-se 1) à paisagem que está no quadro e que é composta de tinta sobre a tela; 2) ao próprio objeto que se encontra fora do quadro (a própria paisagem, que está na natureza, com as árvores, as flores, etc.). Twardowski observa que, em cada um dos casos, o adjetivo "pintado" assume funções distintas. Ou seja, o adjetivo pode assumir duas funções, (1) modificante ou (2) determinante:

1) Se o adjetivo "pintado" é modificante, ele modifica o sentido original do objeto, como ocorre com as expressões "de brinquedo" e "falso". Uma arma de brinquedo não é uma arma. Um falso amigo não é um amigo. Do mesmo modo, a paisagem pintada, no sentido de uma paisagem feita de tinta, não é uma paisagem.

2) $O$ adjetivo pintado também pode atuar como determinante. Neste caso, ele não modifica o sentido original do termo paisagem. (TWARDOWSKI, 1894:14)

$\mathrm{O}$ adjetivo, no último caso, apenas indica que o objeto possui uma relação de determinado tipo com um determinado ser. A paisagem real, que se encontra na natureza, entrou em relação determinada com o ser humano, na medida em que ela foi trazida à exposição [Darstellung].
Isso se aplica à expressão "objeto representado". O que o termo designa vai depender da função que o adjetivo cumpre. Se o adjetivo funciona como modificante, o objeto representado designa o objeto tal como ele se encontra no ato psíquico, ou seja, o conteúdo. Se o adjetivo "representado" funciona como determinante, então o objeto representado não é um conteúdo, mas o próprio objeto transcendente. Neste último caso, a expressão "objeto representado" apenas informa que o objeto "entrou numa relação inteiramente determinada com um ser [Wesen] capaz de representação. Mas, por isso ele não cessou de ser objeto". (TWARDOWSKI, 2005: 58). O mesmo ocorre, por exemplo, na expressão "objeto perdido". O objeto perdido é um objeto, mas o que faz com que ele seja perdido é sua relação com um ser determinado, a saber, aquele que o possuía e que o perdeu. O objeto deve ser sempre diferenciado do conteúdo. O conteúdo é um componente intrínseco ao ato e que lhe confere sua direção a este ou aquele objeto.

Twardowski busca articular sua teoria da intencionalidade com uma teoria da significação. $O$ significado apreendido cumpre a função de conteúdo do ato. "Quem diz um nome pretende evocar no ouvinte o mesmo conteúdo psíquico que ele cumpre para ele mesmo" (2005: 54). E mais adiante: "[...] esse conteúdo é o que se compreende pela 'significação' [Bedeutung]' (2005:55).

Essa concepção carrega consigo uma série de importantes consequências teóricas. Apreender um significado não é projetar, diante da consciência, uma representação interna do objeto, que serve como substituto do objeto na mente, mas sim tornar-se consciente do próprio objeto

Revista de Filosofia Moderna e Contemporânea

Brasília, vol 3, no 2, 2015. 
referido pelo significado. $O$ que está na mente é apenas o conteúdo e não o objeto. O nome "Oceano Atlântico" nomeia o próprio Oceano e não o conteúdo de meu ato de representar o Oceano. Somos capazes de distinguir nossa imagem mental de algo, do próprio algo. Se alguém me diz que irá me pagar um café, posso até formar a imagem mental do café; mas sei que o que ele irá me pagar não é minha imagem mental do café, mas sim algo que eu posso beber, algo que encontra fora da minha mente.

\section{O princípio de imanência}

Uma das contribuições mais importantes de Twardowski (1894) é ele ter rompido, em seu Opúsculo, com um princípio amplamente difundido no século XIX, compartilhado não só por Brentano, mas também pela maioria dos filósofos da época, a saber, o princípio de imanência (PORTA, 2004: 115). Sua formulação clássica remonta a Locke: "O que quer que seja que a mente perceba em si mesma, e qualquer que seja o objeto imediato da percepção, pensamento, entendimento, eu denomino ideia [idea]" (LOCKE, 1975: 134, tradução própria). Se observarmos que o termo inglês "idea", tal como empregado pelos empiristas, foi traduzido para o alemão pela expressão "Vorstellung", que geralmente é traduzida ao português por "representação", temos que o princípio de imanência também se coloca da seguinte forma: os únicos objetos de que podemos estar diretamente conscientes são nossas próprias representações. Para Twardowski, tal posição é equivocada. Ao representarmos um objeto, o objeto de que estamos conscientes não é nem a própria representação, nem o conteúdo imanente desta representação, mas algo que os transcende. A consciência é consciência de algo transcendente, por meio de algo imanente (conteúdo psíquico). Comparado a Brentano, podemos afirmar que o conceito de intencionalidade em Twardowski assume uma nova forma. A tese brentaniana da intencionalidade como direcionalidade se mantém, mas o lugar para onde o ato aponta se desloca da imanência para a transcendência. Isso resulta na reformulação, com relação a Brentano, da tese do status ontológico do objeto intencionado (PORTA, 2007).

Ao deslocar o objeto da representação para fora do ato e do conteúdo do representar, Twardowski teve que enfrentar vários problemas. Um dos problemas mais importantes é o seguinte: toda representação certamente tem um conteúdo, mas toda representação tem um objeto? A resposta de Twardowski é afirmativa. Mas e se representarmos um centauro ou uma montanha de ouro, haveria de existir tais objetos? A resposta de Twardowski é que ser é diferente de existir. A montanha de ouro é algo, mas não existe realmente. Em suma, Twardowski afirma que o objeto de que estamos conscientes pode ter as seguintes determinações ontológicas: (1) reais ou não reais, (2) possíveis ou impossíveis e (3) existentes ou não existentes (2005: 89; 1894: 40). Mesmo um objeto impossível e inexistente, como um quadrado redondo, é algo. Com isso, podemos afirmar que o quadrado redondo é algo, mas não é possivel e nem existe. Ele possui ser, na medida em que é representado, mas não é algo possível e não existe. 
A influência do conceito de conteúdo de Twardowski na teoria da intencionalidade de Husserl

\section{O problema da relação entre significado e o conteúdo real}

Tendo em vista o que foi apresentado até aqui, a particularidade da impostação do problema husserliano concernente à relação entre significação, consciência e objeto pode ser iluminada se considerarmos a influência de Twardowski. Sabemos que Husserl não só leu atenciosamente a obra de Twardowski, mas também preparou, no ano de 1897, uma resenha sobre a mesma, embora não tenha sido publicada (CAVALLIN, 1997: 28). Em linhas gerais, podemos dizer que Husserl absorve de Twardowski a ideia do significado como conteúdo por meio do qual a consciência se direciona a um objeto transcendente (BOER, 1978).

Husserl, entretanto, critica Twardowski por este último afirmar que o significado é um conteúdo psíquico. O problema, para Husserl, é que Twardowski não soube distinguir dois conceitos de conteúdo, ou seja, “[...] entre o conteúdo em sentido subjetivo (em sentido fenomenológico, descritivo-psicológico, empírico-real) e o conteúdo em sentido objetivo (no lógico, intencional, ideal)". (1901/2012: 42; 1901: 52). Ou seja, o significado ideal apreendido é um conteúdo lógico-ideal, mas não é um conteúdo psíquico. Mas o que leva Husserl a distinguir essas duas formas de conteúdo?

Nos Prolegômenos, Husserl argumenta que reduzir o conteúdo lógico-ideal-objetivo a um conteúdo psíquico implica psicologismo e, consequentemente, relativismo. Todavia, é preciso observar que o argumento só vale caso aceitemos o modo como Husserl caracteriza os conteúdos psíquicos. Caso aceito, o relativismo é consequência necessária. Tudo gira, portanto, em fixar com precisão o que Husserl entende por conteúdo psíquico. É neste ponto que se deve observar atentamente o pressuposto que rege Investigações lógicas: todo conteúdo psíquico é um conteúdo real [reell] (1901/2012: 341; 1901: 374). Partindo daí, podemos formular o seguinte quadro:

1. Tudo o que real é algo singular e sujeito ao tempo (1900: 101).

2. Toda vivência é um evento real.

3. Um enunciado científico deve ter sempre exatamente o mesmo significado, pois, de outro modo, teríamos o relativismo e o ceticismo.

4. Logo, nem a vivência de apreensão nem a vivência de expressão de um significado podem alterá-lo, pois a identidade do significado é condição do acordo intersubjetivo.

5. O significado, uma vez que é sempre idêntico, não pode ser conteúdo psíquico (real) de uma vivência, pois nunca algo real é idêntico a outro algo real.

Devemos observar que a conciliação destas posições apresenta um problema. Afinal, uma das condições do conhecimento científico é que o significado não seja reduzido ao conteúdo psíquico (real), pois se fosse parte real da vivência, ele seria algo singular e irrepetível, o que é incompatível com sua idealidade. Mas, por outro lado, o conteúdo ideal (significado) deve ser apreendido, a fim de propiciar ao ato sua direcionalidade um objeto. Por essa razão, o significado ideal apreendido deve, de algum modo, "entrar" e se tornar real na

Revista de Filosofia Moderna e Contemporânea

Brasília, vol 3, no 2, 2015. 
vivência intencional, e, por outro lado, ele não pode ser reduzido a algo real na vivência. Ou seja, de algum modo o significado apreendido deve ser transcendente e de algum modo ele deve ser imanente. $\mathrm{E}$ isso coloca um grande problema para Husserl.

Esse será um problema a que Husserl se esforça, ao longo das Investigações lógicas, para oferecer uma resposta. Sua solução encontra-se naquilo que ficou conhecido como teoria da instanciação (BOER, 1978). De acordo com tal teoria, as intenções significativas (vivência real de significar) são instâncias (exemplares) do significado em espécie, assim como este vermelho singular é uma instância do vermelho em espécie (a essência do vermelho). Ou seja, o significado ideal é a essência de uma intenção significativa concreta. Tomemos o exemplo de alguém que expressa a um ouvinte o julgamento de que "Sócrates viveu em Atenas". O que o falante transmite ao ouvinte não é nem a sua vivência significativa, nem a sua imagem mental, mas a essência de sua intenção significativa judicativa. Neste sentido, a vivência judicativa do falante e a vivência do ouvinte serão a mesma vivência "em espécie", mas serão distintas quanto ao conteúdo real. É neste sentido que Husserl afirma que "A significação comporta-se, relativamente aos respectivos atos de significar [...] assim como o vermelho in specie se comporta relativamente às tiras de papel que aqui estão, as quais 'têm' todas elas o mesmo vermelho". (1901: 101; cf. 2012: 84). Cada tira de papel possui o seu vermelho individual. Mas cada vermelho individual é um caso singular do vermelho in specie, o qual "não existe realmente nem nesta tira de papel nem onde quer que seja no mundo, nem também, sobretudo, 'no nosso pensamento', na medida em que este pertence também ao domínio do ser real, à esfera da temporalidade." (1901: 101; cf. 2012: 84). Desse modo, o juízo lógico, tomado como entidade ideal, se instancia na vivência de julgar, o raciocínio ideal objetivo se instancia em vivências de raciocinar, os significados de nomes em vivências nominais. Em suma, na comunicação, podemos encontrar alguns elementos chave:

1) O ouvinte e o falante possuem vivências significativas realmente distintas.

2) O objeto referido (objeto intencional) é o mesmo.

3) A essência da vivência significativa (conteúdo ideal) é a mesma.

\section{Conclusão}

Ao longo deste artigo, pudemos observar que a teoria da intencionalidade exige se levar em consideração duas teses e um pressuposto. A primeira tese é que os significados devem ser objetivos e ideais (antipsicologismo). A segunda tese é de que a significação ideal deve se tornar imanente para que seja apreendida (exigência da fundamentação epistemológicofenomenológica da lógica pura). O pressuposto, presente em Investigações lógicas, sobre o qual Husserl busca articular essas duas teses, é que toda imanência é imanência psíquica real [reell]. É a partir destes três elementos que Husserl elabora a teoria da instanciação.

Husserl procura conciliar essas duas teses adotando uma teoria da intencionalidade inspirada na concepção de Twardowski, ao distinguir entre ato, conteúdo e objeto. Essa distinção possibilitava a apreensão imediata de objetos transcendentes (não- 
A influência do conceito de conteúdo de Twardowski na teoria da intencionalidade de Husserl

psíquicos), como objetos lógicos. Mas o problema tornava-se agora fixar uma correta concepção de conteúdo, tomado como elemento mediador entre o ato real e o objeto (real, possível, irreal). A dificuldade de tal problema é que Husserl busca resolvê-lo a partir do pressuposto de que toda imanência é imanência psíquica e, portanto, real. A questão, portanto, era: como o conteúdo ideal "entra" na imanência psíquica, se tornando real na consciência, para conferir direcionalidade ao ato? A resposta, na ocasião, se dá com a teoria da instanciação. O sentido ideal entra no conteúdo real da vivência ao se instanciar na intenção significativa.

É preciso, entretanto, observar que a ideia de que a consciência é realidade psíquica será posteriormente abandonada, com a virada transcendental, que ocorre por volta de 1906/1907. Com a introdução da ideia de uma imanência transcendental, o problema da relação entre significado e consciência se modifica, de modo que Husserl, em obras posteriores, abandona a teoria da instanciação de Investigações lógicas. Mas, nas Investigações lógicas, a ideia de que toda consciência é um fluxo real de vivências é determinante. É essa posição que permite não só clarificar a reformulação husserliana da concepção de intencionalidade de Twardowski, mas também peculiaridade da relação entre imanência e idealidade naquela obra.

\section{Referências bibliográficas}

BOER, T. D. The development of Husserl's thought. The Hague; Boston: Nijhoff, 1978.

BRENTANO, F. C. Psychologie vom empirischen Standpunkt. Leipzig: Verlag von Duncker \& Humblot, 1874.

CAVALLIN, J. Content and object : Husserl, Twardowski, and psychologism. Dordrecht; Boston: Kluwer Academic, 1997.

HUSSERL, E. Logische Untersuchungen 1: Prolegomena zur reinen Logik. Halle a/S.: Niemeyer, 1900.

HUSSERL, E. Investigações lógicas. Segundo Volume. Parte I, Investigações para a fenomenologia e a teoria do conbecimento (P. M. S. Alves \& C. A. Morujão, Trans.). Lisboa: Centro de filosofia da Universidade de Lisboa, 2012.

HUSSERL, E. Investigações lógicas. Segundo Volume. Parte II, Investigações para a fenomenologia e a teoria do conbecimento (C. A. Morujão, Trans.). Lisboa: Centro de filosofia da Universidade de Lisboa, 2007.

HUSSERL, E. Investigações Lógicas: Prolegômenos à Lógica Pura. Rio de Janeiro: Forense universitária, 2014.

LOCKE, J. An essay concerning buman understanding. Oxford: Clarendon Press, 1975.

PORTA, M. A. G. Un análisis del opúsculo de Kasimir Twardowski. .

Revista de Filosofia Moderna e Contemporânea

Brasília, vol 3, no 2, 2015. 
Sintese (Belo Horizonte), 34, 261-282, 2007.

TWARDOWSKI, K. Zur Lehre vom Inhalt und Gegenstand der Vorstellungen : eine psychologische Untersuchung. Wien: A. Hölder, 1894.

TWARDOWSKI, K. Sobre a doutrina do conteúdo e do objeto das representações. In C. BRAIDA (ed.), Três aberturas em ontologia: Frege, Twardowski, Meinong (pp. 43-90). Florianopolis: Rocca Brayde, 2005. 